\title{
Ischemic stroke due to protein $\mathrm{C}$ deficiency
}

Debasish Kumar Saha', ASM Areef Ahsan $^{2}$, Kaniz Fatema ${ }^{3}$, Madhurima Saha ${ }^{4}$, Fatema Ahmed ${ }^{5}$, Md. Asrafuzzaman ${ }^{6}$, MM Morshed $^{7}$, Farhana Raz ${ }^{8}$, Md. Rashidul Hassan ${ }^{9}$, Abdullah Al Ahmed ${ }^{10}$, Md. Harisur Rahman $^{11}$, Natasha Rahman ${ }^{12}$

\begin{abstract}
Cardiovascular diseases are one of the common causes of high morbidity and mortality all over the world. Usually stroke occur in elderly, but stroke in younger group (age <45 years) are increasingly common now-a-days. The disease can occur in young patients without any apparent risk factors. It is therefore important to exclude all aetiological causes in order to reduce their chances for a subsequent event.
\end{abstract}

Key words: Ischemic stroke, ICU, Protein C deficiency.

\section{Case report:}

A 42-year normotensive, nondiabetic, nonsmoker unmarried lady admitted in intensive care unit (ICU) with the complaints of deteroriating level of consciousness and difficulty in breathing for several hours. She also had H/O weakness of left side of the body and slurred speech for 4 days prior to ICU admission, which gradually became worsening. She had no $\mathrm{H} / \mathrm{O}$ convulsion or fever prior to the illness. She had no

1. Dr. Debasish Kumar Saha, FCPS (Medicine), Registrar, Dept of Critical Care Medicine, BIRDEM.

2. Dr. A.S.M. Areef Ahsan, FCPS (Medicine), MD (Chest), MD (Critical Care Medicine), Associate Professor and Head, Dept of Critical Care Medicine, BIRDEM.

3. Dr. Kaniz Fatema, FCPS (Medicine), MD (Critical Care Medicine), Assistant Professor, Dept of Critical Care Medicine, BIRDEM.

4. Dr. Madhurima Saha, FCPS (Medicine), Registrar, Dept of Critical Care Medicine, BIRDEM.

5. Dr. Fatema Ahmed, FCPS (Medicine), MD (Critical Care Medicine), Assistant Professor, Dept of Critical Care Medicine, BIRDEM.

6. Dr. Mohammad Asrafuzzaman, MD $2^{\text {nd }}$ part student, Critical Care Medicine, Dhaka Medical College and Hospital.

7. Dr. Md. Mahbub Morshed, MD $2^{\text {nd }}$ part student, Critical Care Medicine, Dhaka Medical College and Hospital.

8. Dr. Farhana Raz, Resident medical officer, ICU, Popular Medical College and Hospital

9. Dr. Md. Rashidul Hassan, MD student, Cardiology, National Heart Foundation Hospital.

10. Dr. Abdullah Al Ahmed, Honorary medical officer, BSMMU.

11. Dr. Mohammad Harisur Rahman, Resident medical officer, ICU, Popular Medical College and Hospital.

12. Dr. Natasa Rahman, Honorary medical officer, Dhaka Medical College and Hospital.

Corresponding Author:

Dr. Debasish Kumar Saha,

FCPS (Medicine)

Registrar, Dept of Critical Care Medicine, BIRDEM.

Email:debasish81dmc@yahoo.com previous history of arterial or venous thrombosis. On examination, she was found grade 4 unconscious, febrile, pulse- 96 bpm, BP-110/70 mm hg, tachypnoeic with bilateral coarse crepitations and transmitted sound throughout. She had UMN type of paralysis of left side of body. Immediate endotracheal intubation was done for tracheobronchial toileting. CT Scan of head which done before admission in ICU showed right temporoparietal infarction with cerebral edema. MRI Brain showed acute infarct at both cerebellar, right temporal, basal ganglia and both parieto-occipital regions. Lab investigations showed increased total WBC count with neutrophilic leucocytosis. Blood sugar, lipid
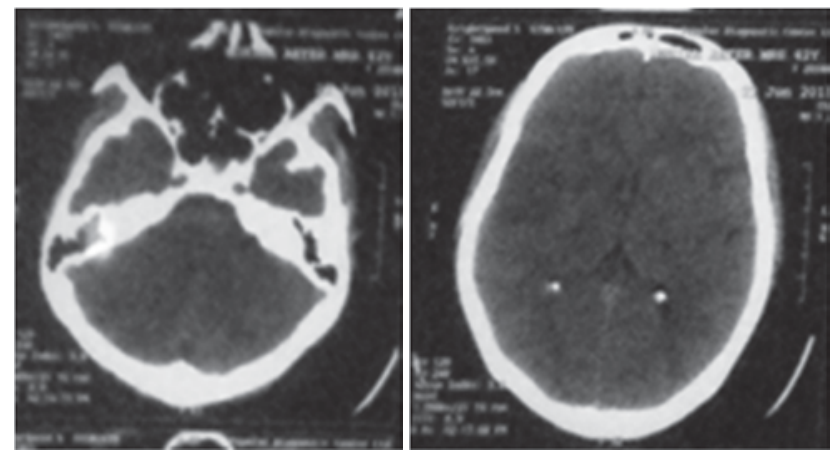

Figure 1: CT head showing right temporoparietal infarction with cerebral edema.

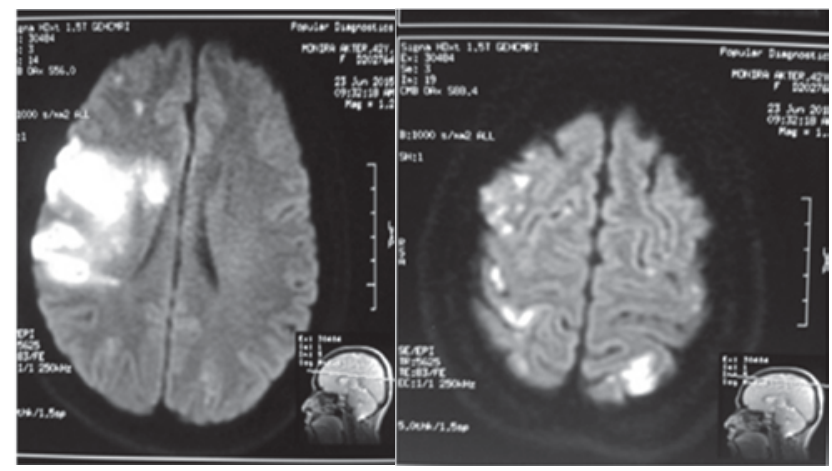

Figure 2: MRI brain showing acute infarct at right temporal, basal ganglia and both parieto-occipital regions 
profile, renal function and liver function tests were normal. ECG was normal, CXR revealed right basal pnumonitis. Cultures of blood, urine and tracheal aspirate showed no growth. Echocardiogram was normal. Investigations were done to find out cause. ANA, Anti DS DNA, pANCA, cANCA and Antiphospholipid antibody tests were normal. Syphilis serology was also normal. Serum protein S -71\% (50\%-120\%), protein C-53\% (70\%-130\%), Homocysteine 8.12 umol/1 (5\%-15\%). Real time carotid imaging showed nonsignificant diameter reduction in both sides.

So finally, the diagnosis of acute infarctive stroke due to protein $\mathrm{C}$ deficiency along with aspiration pneumonia was established. Inj LMWH started and followed by oral anticoagulant. Antibiotics started accordingly along with other supportive management. Her condition was gradually improving, but unfortunately the patient was discharged against medical advice due to financial constraints.

\section{Discussion:}

Stroke means different pathological processes. $85 \%$ of the strokes are ischemic and 15\% hemorrhagic. Even among the patients with ischemic stroke, a number of different pathological processes are responsible. As cardioembolism, large artery disease with arteriolosclerosis and thromboembolism, and small artery disease. ${ }^{1}$ In some cases, causes remain unclear. ${ }^{2-4}$ Protein $\mathrm{C}$ deficiency is a rare cause of ischemic stroke. This deficiency can occur alone or in combination with protein S deficiency or other anticoagulant deficiency. Protein S deficiency has been associated with cerebral arterial ischemia more often than protein $\mathrm{C}$ deficiency. ${ }^{1}$

In our patient, ischemic stroke with clinical symptoms of hemiplegia, motor dysphasia followed by deteroriation of consciousness was established by CT Scan and MRI Brain. Embolic infarction from a cardiac source or arterio-arterial embolism due to preexisting carotid artery sclerosis could largely be excluded as could immunological diseases. The patient's protein $\mathrm{C}$ was significantly decreased and anticoagulation was started. As we did not get any positive family history, we suggested to do serum protein $\mathrm{C}$ level for her siblings and parents; but unfortunately they refused to do at that time.
Protein $\mathrm{C}$ deficiency may be inherited and acquired. Inherited deficiency occurs as an autosomal dominant trait with incomplete penetrance. For acquired cases, severe sepsis, DIC, liver diseases, warfarin therapy, chemotherapy drugs are important causes. In our patient, it could be argued that acute thrombosis by itself could lower the protein $\mathrm{C}$ concentration, but here the tests was done after acute event subsided (several days after the stroke event, and protein $\mathrm{C}$ has a short half life, around 8 hours). Moreover, protein $\mathrm{C}$ concentration do not differ significantly between patients suffering from acute stroke and healthy control. ${ }^{5}$

It remains unclear, however, why persons with heterozygous protein $\mathrm{C}$ deficiency do not present more often with arterial thromboembolic events. ${ }^{6}$ Sedentary lifestyle could have imposed additional risk in our patient, but other still unknown factors might also have contributed.

\section{Conclusion:}

It is thus emphasized that protein $\mathrm{C}$ deficiency though rarely associated with thrombotic events. But when dealing with a case of cerebral infarction in young patient, screening for protein $\mathrm{C}$ and protein $\mathrm{S}$ should be made especially when patients are below 45 years. A positive result requires immediate initiation of anticoagulant therapy; and chances of subsequent events could be reduced thereby.

\section{References:}

1. Patel ML, Sachan R, Gupta KK, Seth GIschemic Stroke in Young due to Combined Protein C and S Deficiency. JCR 2013;3:19-23

2. Bogousslavsky J, Regli F:ischemic stroke in adults younger than 30 years of age .Cause and prognosis. Arch Neurol 1987; 44:479-482

3. Hart RG, Miller VT:Cerebral stroke in young adult: A practical approach.stroke 1983;14:110-114

4. Grindal AB, Cohen RJ, Saul RF, Taylor JR: Cerebral infarction in young adult. Stroke 1978:9:39-42

5. D' Angelo A, landi G, D' Angelo SV, Orazio EN, Boccardi E, Candelise L, Mannucci PM: Protein C in acute stroke. Stroke 1988; 19:579-583.

6. Kohler J, Kasper J, Witt I, von Reutern GM. Ischemic stroke due to protein C deficiency. Stroke 1990 Jul 21 7:1077-80 